\title{
Are the recommendations to use perioperative $\beta$-blocker therapy in patients undergoing noncardiac surgery based on reliable evidence?
}

\section{P.J. Devereaux, Salim Yusuf, Homer Yang, Peter T.-L. Choi, Gordon H. Guyatt}

$\mathrm{O}$ $f$ the approximately 26 million North Americans who undergo noncardiac surgical procedures every year, ${ }^{1,2} 1 \%-5 \%$ suffer a major perioperative cardiovascular event. ${ }^{1,3}$ Perioperative ischemic events prolong hospital stays by a mean of 11 days ${ }^{4}$ and cost the US economy approximately $\$ 20$ billion a year. ${ }^{1}$ Several large studies have evaluated approaches to estimating perioperative cardiovascular risk, but practically no large randomized controlled trials (RCTs) have evaluated interventions to decrease perioperative cardiovascular events. ${ }^{5}$

After the American College of Physicians had approved guidelines on perioperative cardiac care, the 2 authors of the guidelines inserted their own recommendation for perioperative atenolol therapy for patients with coronary artery disease undergoing noncardiac surgery; this was done on the basis of the findings of a single trial. ${ }^{6}$ More recently, the American College of Cardiology / American Heart Association practice guidelines for noncardiac surgery stated, "there are still very few randomized trials of medical interventions before noncardiac surgery ... and they do not provide enough data from which to draw firm conclusions or recommendations." ${ }^{5} \mathrm{Nev}-$ ertheless, these guidelines categorized the use of $\beta$-blockers in patients undergoing vascular surgery with ischemia detected during preoperative testing as a class I recommendation, and they gave a class IIa recommendation to use perioperative $\beta$ blocker therapy in patients with preoperative untreated hypertension, known coronary artery disease or major risk factors for coronary disease. ${ }^{5}$ In this article, we will discuss the evidence underlying these recommendations.

\section{Effect of $\beta$-blockers on perioperative outcomes}

A recent meta-analysis ${ }^{7}$ included 11 RCTs that studied the use of perioperative $\beta$-blocker therapy; a total of 866 patients were enrolled in the trials, of whom 475 received $\beta$-blocker therapy. Only 7 of the 11 RCTs reported any major adverse events within the first 30 days of surgery; overall, there were only 20 deaths (of which 15 were cardiac) and 18 cases of nonfatal myocardial infarction. The meta-analysis failed to include a nonfatal myocardial infarction that occurred in 1 of the $\mathrm{RCTs}^{8}$ and incorrectly assumed that the myocardial infarctions in another trial ${ }^{9}$ were nonfatal. Table 1 provides an overview of these results.

The $7 \beta$-blocker trials did not demonstrate a significant impact on the total number of deaths, but suggested a reduction in the number of deaths from cardiac events, as well as nonfatal myocardial infarctions. In the metaanalysis, there were 3 cardiac deaths in the $\beta$-blocker group and 12 in the control group; 11 of these 15 deaths, and 9 of the 18 nonfatal myocardial infarctions, occurred in a trial by Poldermans and colleagues. ${ }^{8}$

The results from these trials are promising, but they warrant cautious interpretation in light of the very small number of events and the substantial reliance on the results of 1 small trial. ${ }^{8}$ If even 1 or 2 "negative" trials remain unpublished, this could undermine the findings of the meta-analysis. To establish moderate $(25 \%)$ relative risk reductions convincingly, given a control event rate of

Table 1: Summary of outcomes of perioperative $\beta$-blocker RCTs

\begin{tabular}{|c|c|c|c|c|}
\hline Outcome & $\begin{array}{l}\text { Patients receiving } \\
\beta \text {-blocker therapy } \\
\qquad n=475\end{array}$ & $\begin{array}{l}\text { Control } \\
\text { patients } \\
n=391\end{array}$ & OR $(95 \% \mathrm{Cl})$ & $p$ value \\
\hline Death & 8 & 12 & $0.63(0.25-1.54)$ & 0.30 \\
\hline Death from cardiac event & 3 & 12 & $0.25(0.09-0.73)$ & 0.01 \\
\hline \multicolumn{5}{|l|}{$\begin{array}{l}\text { Death from cardiac event, } \\
\text { excluding results from }\end{array}$} \\
\hline Poldermans et $\mathrm{al}^{8}$ & 1 & 3 & $0.43(0.06-2.96)$ & 0.40 \\
\hline Nonfatal MI & 2 & 16 & $0.18(0.06-0.52)$ & $<0.01$ \\
\hline $\begin{array}{l}\text { Nonfatal MI, excluding } \\
\text { results from Poldermans et } \mathrm{al}^{8}\end{array}$ & 2 & 7 & $0.32(0.09-1.10)$ & 0.07 \\
\hline Bradycardia* & 90 & 26 & $3.76(2.45-5.77)$ & $<0.01$ \\
\hline
\end{tabular}

Note: $\mathrm{RCT}=$ randomized controlled trial, $\mathrm{OR}=$ odds ratio, $\mathrm{Cl}=$ confidence interval, $\mathrm{MI}=$ myocardial infarction . *Bradycardia: most commonly defined as a persistent heart rate $<50$ beats $/ \mathrm{min}$. 
$10 \%$, an RCT would require at least 350 , and ideally 650 , events. ${ }^{10}$ The perioperative $\beta$-blocker RCT data included only 38 events.

Furthermore, the relative risk reductions of $75 \%-80 \%$ in this meta-analysis are inconsistent with the results of RCTs that showed benefits of cardiovascular therapies, which have generally demonstrated relative risk reductions in the order of $20 \%-35 \%$. A host of mechanisms, including increases in adrenergic activity, free fatty acid levels, platelet reactivity, plasminogen activator inhibitor I, factor VIII-related antigen levels, inflammation, and decreases in antithrombin III levels, probably mediate perioperative cardiovascular events. ${ }^{8,11-14}$ Only a few of these mechanisms (e.g., decreasing adrenergic activity and free fatty acid levels) are targeted by $\beta$-blockers. Given the number of important pathogenic mechanisms that are unaffected by $\beta$ blockers, relative risk reductions much greater than $25 \%$ are implausible.

The RCT by Poldermans and colleagues that dominates the meta-analysis warrants further scrutiny. This trial evaluated the efficacy of bisoprolol therapy in patients with a positive dobutamine echocardiography study who were undergoing elective vascular surgery. There are a number of reasons for concern about their findings: the study included only 112 patients; few events occurred (20 total); and the trial was not blinded. The investigators terminated the trial because interim analysis suggested a large benefit. Empirical data caution us to be skeptical about unexpected large treatment effects in studies that are terminated early. ${ }^{15}$ Further, the benefits appear too good to be true (relative risk reductions of $100 \%$ for nonfatal myocardial infarction, and $80 \%$ for cardiac death). These results are inconsistent with those of RCTs of $\beta$-blocker therapy in tens of thousands of patients with acute myocardial infarction and chronic congestive heart failure, which have consistently demonstrated relative risk reductions of $15 \%-35 \%$. If this were true, we would be seeing virtually no cardiac events in patients treated with $\beta$-blockers in clinical practice. But this is not the case. Although the findings of this trial are important, they need to be confirmed in a large, well-designed RCT.

With respect to long-term benefits, a single RCT involving 200 patients undergoing noncardiac surgery became the basis for the recommendation for perioperative $\beta$-blocker therapy by the authors of the ACP guidelines. ${ }^{9}$ In this trial, atenolol or placebo was administered to patients for a maximum of 7 postoperative days. After 2 years of follow-up, 9 deaths had occurred in the atenolol group and 21 in the placebo group (a relative risk reduction of $55 \%, p=0.02) .{ }^{9}$ However, the authors included only deaths that occurred after patients had stopped taking the trial medication. Given that perioperative $\beta$-blockers have the greatest potential for impact during the period when patients are taking these drugs, it is inappropriate to exclude these events from the analysis. Including the data from the first 7 postoperative days (when patients were re- ceiving the trial medication) gives a total of 13 deaths in the atenolol group and 23 in the placebo group (a true intention-to-treat analysis), and the difference loses statistical significance $(p=0.1)$. The paucity of events, the implausibly large magnitude of the effect and the nonsignificant results when one includes all deaths during the 2-year follow-up call into question this trial's conclusions.

\section{Interpreting the evidence}

Given the current evidence, recommendations to consider perioperative $\beta$-blocker therapy are reasonable. It is important, however, to distinguish a weak from a strong recommendation. For instance, for more than a decade the evidence warranted a recommendation to offer postmenopausal women hormone replacement therapy. But the limitations of that evidence mandated a weak recommendation and suggested that women unwilling to accept potential risk for uncertain benefit should avoid the treatment. The situation with $\beta$-blocker therapy is similar, in that we have relatively sparse and unreliable data on the potential risks and benefits of using $\beta$-blockers in patients undergoing noncardiac surgery.

The investigators of the perioperative $\beta$-blocker trials have provided extremely important data. The current available evidence from their trials identifies the need and provides the impetus for a large, adequately powered RCT to definitively establish the benefits and risks associated with perioperative $\beta$-blocker therapy. To address this need, an international group of investigators has initiated a large RCT, the PeriOperative ISchemic Evaluation (POISE) trial, funded by the Canadian Institutes of Health Research. The study is designed to evaluate the efficacy of 30 days of controlled release metoprolol to prevent major perioperative cardiovascular events (cardiovascular death, nonfatal myocardial infarction and nonfatal cardiac arrest) in patients undergoing all types of noncardiac surgery. The POISE trial is currently recruiting patients from 75 centres in 9 countries. To date, more than 1800 patients have been enrolled; a total recruitment of 10000 patients is planned.

Once we acknowledge that the evidence in favour of using perioperative $\beta$-blockers is modest, and large trials are needed, what should physicians do for their patients? Some physicians will find the available data suggestive, but by no means definitive, and join perioperative $\beta$-blocker trials. Others may feel more inclined to use a $\beta$-blocker in selected patients, accepting the limitations of current data. However, it would only be reasonable for physicians to share with patients their knowledge about the weakness of the evidence and the lack of clear data on safety. Patients unwilling to accept certain risks for unknown benefits would be best advised to avoid the intervention until the role of $\beta$-blocker therapy in noncardiac surgery has been clarified by sufficiently powered clinical trials. 
This article has been peer reviewed.

From the Department of Medicine (Devereaux, Yusuf, Guyatt), the Population Health Research Institute (Devereaux, Yusuf) and the Department of Clinical Epidemiology and Biostatistics (Guyatt), McMaster University, Hamilton, Ont., and from the Department of Anesthesia, University of Ottawa, Ottawa, Ont. (Yang), the Vancouver Coastal Health Research Institute and the Department of Anesthesia, University of British Columbia, Vancouver, BC (Choi).

Competing interests: Drs. P.J. Devereaux and Homer Yang are the Co-Principal Investigators of the POISE Trial, Dr. Salim Yusuf is the Chair of the POISE Steering Committee, Dr. Gordon Guyatt is a member of the POISE Steering Committee and the Chair of the Adjudication Committee, and Dr. Peter Choi is a member of the POISE Steering Committee.

Contributors: P.J. Devereaux undertook the data analysis. All coauthors made significant contributions to the design of the manuscript and interpretation of the data. They provided critical revisions and gave final approval of the submitted version to be published.

Dr. P.J. Devereaux is supported by a Canadian Institutes of Health Research, Senior Research Fellowship Award. Dr. Salim Yusuf holds an endowed Chair of the Heart and Stroke Foundation of Ontario and is a Senior Scientist of the Canadian Institutes of Health Research. Dr. Peter Choi is funded by a Vancouver Coastal Health Research Institute Mentored Clinician Scientist Award. The POISE trial is funded by the Canadian Institutes of Health Research and the Commonwealth Government of Australia, National Health and Medical Research Council (NHMRC) Grant, and the study drug is provided by AstraZeneca.

\section{References}

1. Mangano DT. Perioperative cardiac morbidity. Anesthesiology 1990;72:153-84.

2. Devereaux PJ. Perioperative cardiac risk assessment and modification in patients undergoing noncardiac surgery [workshop presentation] Annual Conference of Canadian Society of Internal Medicine. October 2002; Halifax.

3. Lee TH, Marcantonio ER, Mangione CM, Thomas EJ, Polanczyk CA, Cook $\mathrm{EF}$, et al. Derivation and prospective validation of a single index for cardiac risk of major noncardiac surgery. Circulation 1999;100(10):1043-9.

4. Fleischmann KE, Goldman L, Young B, Lee TH. Association between cardiac and noncardiac complications in patients undergoing noncardiac surgery: outcomes and effects on length of stay. Am 7 Med 2003;115:515-20.

5. Eagle KA, Berger PB, Calkins H, Chaitman BR, Ewy GA, Fleischmann KE, et al. ACC/AHA guideline update for perioperative cardiovascular evaluation for noncardiac surgery - executive summary. A report of the American College of Cardiology / American Heart Association Task Force on Practice Guidelines (Committee to Update the 1996 Guidelines on Perioperative Cardiovascular Evaluation of Noncardiac Surgery). 7 Am Coll Cardiol 2002; 39(3):542-53.

6. Palda VA, Detsky AS. Perioperative assessment and management of risk from coronary artery disease. Ann Intern Med 1997;127:313-28.

7. Stevens RD, Burri H, Tramer MR. Pharmacologic myocardial protection in patients undergoing noncardiac surgery: a quantitative systematic review. Anesth Analg 2003;97:623-33.

8. Poldermans D, Boersma E, Bax JJ, Thomson IR, van de Ven LL, Blankensteijn JD, et al. The effect of bisoprolol on perioperative mortality and myocardial infarction in high-risk patients undergoing vascular surgery. $N$ Engl $f$ Med 1999;341(24):1789-94.

9. Mangano DT, Layug EL, Wallace A, Tateo I. Effect of atenolol on mortality and cardiovascular morbidity after noncardiac surgery. N Engl f Med 1996; 335:1713-20.

10. Yusuf S, Collins R, Peto R. Why do we need some large, simple randomized trials? Statistics Med 1984;3:409-20.

11. McDaniel MD, Pearce WH, Yao JS, Rossi EC, Fahey VA, Green D, et al. Sequential changes in coagulation and platelet function following femorotibial bypass. 7 Vasc Surg 1984;1(2):261-8.

12. Rosenfeld BA, Beattie C, Christopherson R, Norris EJ, Frank SM, Breslow MJ, et al, for the Perioperative Ischemia Randomized Anesthesia Trial Study Group. The effects of different anesthetic regimens on fibrinolysis and the development of postoperative arterial thrombosis. Anesthesiology 1993; 79(3):435-43.

13. Schillinger M, Domanovits H, Bayegan K, Holzenbein T, Grabenwoger M, Thoenissen J, et al. C-reactive protein and mortality in patients with acute aortic disease. Intensive Care Med 2002;28(6):740-5.

14. Flinn WR, McDaniel MD, Yao JST, Fahey VA, Green D. Antithrombin III deficiency as a reflection of dynamic protein metabolism in patients undergoing vascular reconstruction. 7 Vasc Surg 1984;1:888-95.

15. Wheatley KW, Clayton D. Be skeptical about unexpected large apparent treatment effects: the case of an MRC AML 12 randomization. Control Clin Trials 2003;24:66-70.

16. Grady D, Rubin SM, Petitti DB, Fox CS, Black D, Ettinger B, et al. Hormone therapy to prevent disease and prolong life in postmenopausal women. Ann Intern Med 1992;15;117(12):1016-37.

Correspondence to: P.J. Devereaux, McMaster University, Faculty of Health Sciences, Clinical Epidemiology and Biostatistics, Room 2C8, 1200 Main St. W. Hamilton ON L8N 3Z5; fax 905 5261353; philipj@mcmaster.ca

Current POISE trial participants: Trial Coordinator: J. Finocchi; Trial Manager: S. Chrolavicius. National Coordinators: Australia/New Zealand/Hong Kong, Dr. K. Leslie; Canada, Drs. R. Hudson, M. Jacka, T. Schricker and B. Warriner; Colombia, Drs. P. Ibarra and J. Carlos Villar; Hungary, Dr. Matyas Keltai; Norway, Dr. J. Raeder; United Kingdom, Drs. P. Foex, J. Giles and J. Sear; Principal Investigators: Australia, Drs. D. Beilby, S. Bolsin, R. Kerridge, T. McCulloch, P. Myles, M. Paech, P. Peyton, M. Priestly and D. Wolfers; Canada, Drs. J. Akhtar, N. Ali, N. Badner, C. Baer, W.S. Beattie, H. Bertozzi, A. Boulton, G. Bryson, J. Campeau, D. Chauret, D. Cook, B. Davies, G. Doak, G. Doig, G. Dresser, P. Duffy, A. Fayad, K. Gilbert, D. Hughes, C. Kamra, L. Lanthier, C. MacDonald, P. MacDonald, R. Martinek, R. Merchant, D. Miller, J. Misterski, R. Mizera, J. Parlow, M. O'Reilly, J. Ostrander, S. Sivakamaran, M. Turabian, D. Twist, J. VanVlymen, D. Wong and K. Zarnke; Colombia, Drs. J. Chona, E. Duarte, E. Javier Manrique, R. Plata, G. Rangel; Hong Kong, Dr. M. Chan; Hungary, Drs. K. Darvas, J. Regoly-Merei; New Zealand, Drs. S. Walker, Y. Young; Norway, Dr. A. Hunting; United Kingdom, Dr. J. Ross 